\title{
Effect of dehulling on nutritive value of quinoa seed
}

\author{
Gitika Sharma, Sarla Lakhawat and Sunil Kumar
}

In this era of ever-increasing world population, newer food and feed crops that have been hitherto neglected are gaining recognition. The rejection of such lesser-known food crops has been due not to any inferiority but to the lack of research resources in the place of origin and often to their being scorned as "poor people's plants." Quinoa whole and Quinoa dehulled was analyzed and reported that Depending on the chemical analysis of Quinoa whole, Quinoa dehulled, the Quinoa dehulled considered nutritionally dense due to its better nutritional composition and low anti-nutrients than Quinoa whole.

Key Words : Chenopodium quinoa, Pseudo cereals, Antioxident

How to cite this article : Sharma, Gitika, Lakhawat, Sarla and Kumar, Sunil (2020). Effect of dehulling on nutritive value of quinoa seed. Food Sci. Res. J., 11(2): 62-69, DOI : 10.15740/HAS/FSRJ/11.2/62-69. Copyright@ 2020: Hind Agri-Horticultural Society.

Gitika Sharma, Krishi Vigyan Kendra (Agriculture University), Anta, Baran (Rajasthan) India

Email: gitikasharma718@gmail.com

Associate Authors' :

Sarla Lakhawat, Department of Foods Science and Nutrition, College of Community and Applied Science, Maharana Pratap University of Agriculture and Technology, Udaipur (Rajasthan) India

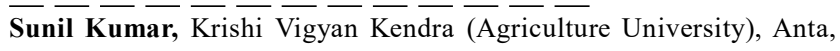
Baran (Rajasthan) India 